\title{
Grafting nanocellulose with diethylenetriaminepentaacetic acid and chitosan as additive for enhancing recycled OCC pulp fibres
}

\author{
Ao Li $\cdot$ Dezhong Xu $\cdot$ Mengnan Zhang $\cdot$ Shengzhong Wu $\cdot$ Yu Li $\cdot$ \\ Weisheng Sun - Yonghui Zhou - Omar Abo Madyan - Mizi Fan (D) \\ Jiuping Rao
}

Received: 14 September 2021 / Accepted: 17 December 2021

(C) The Author(s) 2022

\begin{abstract}
This paper develops a novel paper additive for effectively recycling old corrugated container (OCC) by functionalizing nanocellulose (NC) with diethylenetriaminepentaacetic acid (DTPA) and chitosan (CS), and investigate the reinforcing mechanisms and effect of the developed additive on the physical properties of recycled OCC pulp handsheets. The tensile, tear and burst index, air permeability, tensile energy absorption (TEA), and drainage performance of the recycled OCC handsheets are examined. Fourier transform infrared FTIR) spectroscopy, thermal gravimetric analysis (TGA) and scanning electron microscopy (SEM) are used for the chemical and microstructure characterization of both $\mathrm{NC}$ based
\end{abstract}

A. $\mathrm{Li} \cdot \mathrm{D} . \mathrm{Xu} \cdot \mathrm{M}$. Zhang $\cdot \mathrm{S}$. Wu .

Y. Li · M. Fan $(\bowtie) \cdot$ J. Rao $(\bowtie)$

College of Materials Engineering, Fujian Agriculture and

Forestry University, 350108 Fuzhou, China

e-mail: fanfafu@gmail.com

J. Rao

e-mail: fafurjp@163.com

W. Sun

College of Engineering, Zhejiang Agricultural and

Forestry University, 311300 Hangzhou, China

Y. Zhou · O. A. Madyan · M. Fan

Nanocellulose and Biocomposites Research Centre,

Brunel University London, UB8 3PH London, UK

O. A. Madyan

Department of Engineering, CSIC, University of

Cambridge, CB2 1PZ Cambridge, UK additives and paper from recycled OCC pulp. The results show that functional groups on the NC based additive, such as carboxyl, amino and hydroxyl groups, can bond with the hydroxyl groups on the recycled OCC fibres to generate a chemical bond. This leads to an increase in the crosslinks and bonding area between the fibres, which increases their tensile strength and improves their recycling rate. SEM shows that the paper with NC based additives had tighter inter-fibre bonds and smaller paper pore structure. Addition of $0.3 \%$ NC-DTPA-CS additive results in optimal properties of the recycled OCC paper with an increase by $31.64 \%, 22.28 \%$ and $36.6 \%$ of tensile index, tear index, burst index respectively, and the air permeability decreases by $36.92 \%$. 


\section{Graphical Abstract}

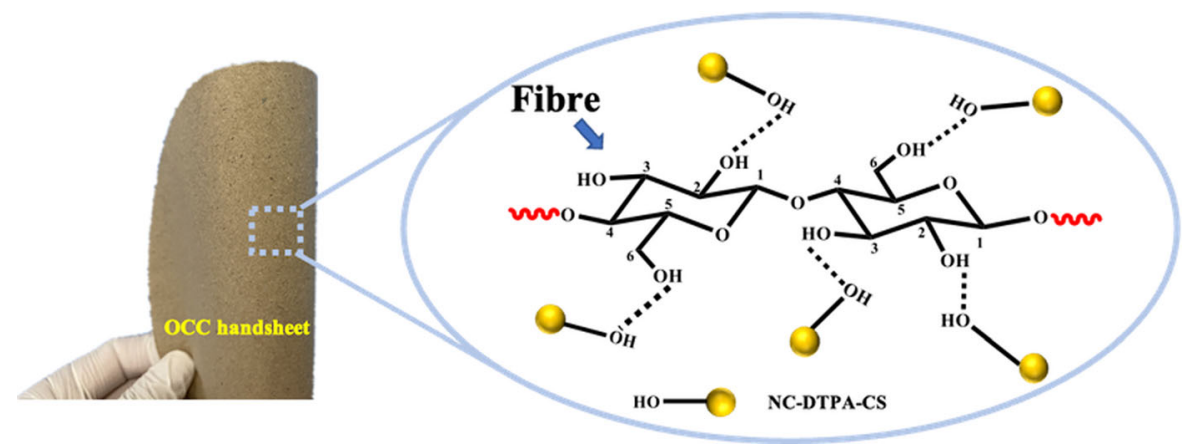

Keywords Nanocellulose (NC) - Old corrugated container (OCC) · NC-DTPA-CS · Additive · Paper property

\section{Introduction}

Recently, nanocellulose (NC) has received increasing attention due to its attractive inherent properties such as biodegradability (Mishra et al. 2018), low density(Dufresne 2010), high surface area (Klemm et al. 2018), stiffness (Hubbe et al. 2017), flexibility (Tanaka et al. 2015), high aspect ratio and unique rheology as well as the ability to form effective hydrogen bonds within the entire cellulose chain or other polymeric matrix ( $\mathrm{Li}$ et al. 2021). The polyhydroxy chemistry of NC offers many derivatization opportunities for many industries and researchers. NC and its derivatives-based materials have been widely used in food (Velasquez-Cock et al. 2019), paper (Espinosa et al. 2016), and composite materials (Pei et al. 2011), especially in the paper industry. However, there are still some deficiencies in the paper industry, such as the poor retention of NC (Hollertz et al. 2017); forming a tightly entangled network structure of the slender filaments is favoured for recycling but may cause drainage problems (Ahola et al. 2008; Onur et al. 2019); its limited adsorption capacity to pulp fibres and moderate reinforcement effect, which often makes it difficult to achieve specific strength requirements (Yang et al. 2017). Some researchers have addressed these negative effects by modifying the NC, adding fillers or multi-reinforced systems by considering the complex interactions between cellulose pulp, NC, mineral fillers and various commonly used additives (Espinosa et al. 2019; He et al. 2017; Khalil et al. 2014). The molecular structure of NC itself is characterized by a linear polymer of D-glucose linked by $\beta$-1,4-glycosidic bonds, with three hydroxyl groups per D-glucose unit (C2, C3 and C6 atoms, respectively), which are easily substituted and the introduction of functional groups can confer potential functionality (French 2017; Mahfoudhi and Boufi 2017; Poletto et al. 2013). The presence of abundant primary and secondary hydroxyl groups on the surface of NC can be easily used to modify the biopolymer and produce cellulose derivatives or grafted to different materials. The abundant - $\mathrm{OH}$ groups on surface can also be attracted to each other electrostatically (through hydrogen bonding), leading to chain building ordered structures (Hubbe et al. 2015; Kalia et al. 2011). This hydrogen bonding across polysaccharides has a key role in adhesive applications related to the adhesion between NC and other materials (Gardner et al. 2008). This role is particularly prominent in the composite and paper industries (Amini et al. 2017).

Old corrugated container (OCC) is a major component of the recycling market. The fibres of OCC pulp are degraded shorter and weaker than the original fibres, and the bond between the short fibres is significantly weaker, which results in a very poor mechanical strength of the paper in addition to relatively weak strength of short fibres themselves compared to that of long/virgin fibres. Reusing OCC also requires dealing with pulp contaminants, the composition and types of which are extremely complex, such as adhesive impurities, inks, certain anions, 
etc. (Holbery et al. 2000). These adhesive impurities can generate deposits in paper-making equipment and also cause paper breakage phenomena, which prolongs production time and reduces productivity $(\mathrm{Wu}$ et al. 2010). The presence of anionic litter could cause the original strength agent to lose its efficiency and has a certain electrostatic repulsion between the fibres (Sheikhi and Talaeipour 2011; Zhao et al. 2014). Therefore, in the OCC recycling process, the removal and utilization of various impurities and the improvement of paper strength are the keys for the quality of recycled OCC pulp and decide whether the recycling of OCC can be further developed. Chitosan is a high molecular weight linear carbohydrate, chemically similar to cellulose, prepared by hydrolysis of the $\mathrm{N}$-acetyl group of the natural polymer chitin (Jiang et al. 2015; Tu et al. 2017). It is rich in functional groups, such as hydroxyl, amino and acetylamino groups, which facilitate the formation of hydrogen bonds with the hydroxyl groups in the cellulose fibres of the pulp and are effective as dry strength agents in the paper industry (Rahmaninia and Khosravani 2015). In this paper, a novel paper additive nanocellulose derivative (NC-DTPA-CS) was developed by modifying NC with diethylenetriaminepentaacetic acid (DTPA) and cross-linking it with chitosan (CS). It is then applied as a paper reinforcement to enhance the tensile properties of recycled paper, and to improve the recyclability of OCC by forming chemical bonds as well as producing hydrogen bonding to bind the fibres to the OCC by making them crosslinked to a complex degree. The additive also bridges the pulp fibres with anion. The development could lead to improving the efficient recovery of waste paper resources, reducing greenhouse gas emissions, alleviating environmental pressure, and implementing a low-carbon economy with low energy consumption, low emissions, and low pollution, which has tremendous economic and social benefits.

\section{Materials and methods}

\section{Materials}

The old corrugated container (OCC) used in this study was obtained from Qingshan Paper Co Ltd. The moisture content of OCC was $8.48 \%$. Nanocellulose (NC, $1.02 \mathrm{mmol} / \mathrm{g}$ carboxyl content, $2.5 \pm 0.5 \%$ solid content). Chitosan (CS, degree of deacetylation (DD) $80-5 \%$, viscosity $50-800 \mathrm{mPa} \cdot \mathrm{s}$, viscosity average molecular weight $1000 \mathrm{kDa}$, burning residue $\leq 1.5 \%$ and insoluble in water). $\mathrm{NC}$ and chitosan (CS) were provided by Sinopharm Chemical Reagent Co Ltd., DTPA by Shanghai Maclean Biochemical Technology Co Ltd., sodium hydroxide $(\mathrm{NaOH})$ by Xilong Technology Co Ltd., and sodium hypophosphite (SHP) and acetic acid $\left(\mathrm{CH}_{3} \mathrm{COOH}\right)$ by Tianjin Zhiyuan Chemical Reagent Co Ltd.

Fabrication of advanced NC additives

$5 \mathrm{~g}$ of DTPA was dissolved in $20 \mathrm{~mL}$ of $\mathrm{NaOH}$ solution with $\mathrm{pH}=12$ and $1 \mathrm{~g}$ of SHP was added and heated at $65{ }^{\circ} \mathrm{C}$ for $24 \mathrm{~h}$ to make it fully reacted. After $5 \mathrm{~g}$ of $\mathrm{NC}$ was added, the mixture was stirred vigorously by hand with a glass rod and placed in an electric thermostatic blast dryer at $130{ }^{\circ} \mathrm{C}$ for $4 \mathrm{~h}$. The product was washed with distilled water and filtered several times to remove the unreacted material, and then air-dried overnight at $50{ }^{\circ} \mathrm{C}$ in an electric thermostatic blast dryer to obtain a product called NCDTPA. After dissolving $1 \mathrm{~g}$ of CS in $50 \mathrm{~mL}$ of $1.5 \%$ acetic acid solution and $1 \mathrm{~g}$ NC-DTPA in $50 \mathrm{~mL}$ of deionized water, both solutions were mixed together and reacted in a magnetic stirrer at $80{ }^{\circ} \mathrm{C}$ for $3 \mathrm{~h}$ to obtain the product called NC-DTPA-CS. The reaction mechanism is shown in Fig. 1.

OCC pulp disintegration and refining

OCC samples were cut into pieces and soaked in deionized water for $24 \mathrm{~h}$. The OCC pulp samples were disintegrated and refined with valley beater (T06-23, Xianyang Tongda Light Industrial Equipment Co., Ltd, China) according to TAPPI T200 sp-01 method. The Schopper-Riegler value of the beaten pulp was 37 ${ }^{\circ} \mathrm{SR}$ according to ISO 5267-1:1999 in pulp beaten degree tester (J-DJY100, Sichuan Changjiang Paper Instrument Co., China).

Preparation of OCC handsheets paperboard containing additives

To prepare the OCC handsheets, the OCC fibre suspension (which was previously disintegrated and refined) was initially diluted to $0.2 \mathrm{wt} \%$ and then 

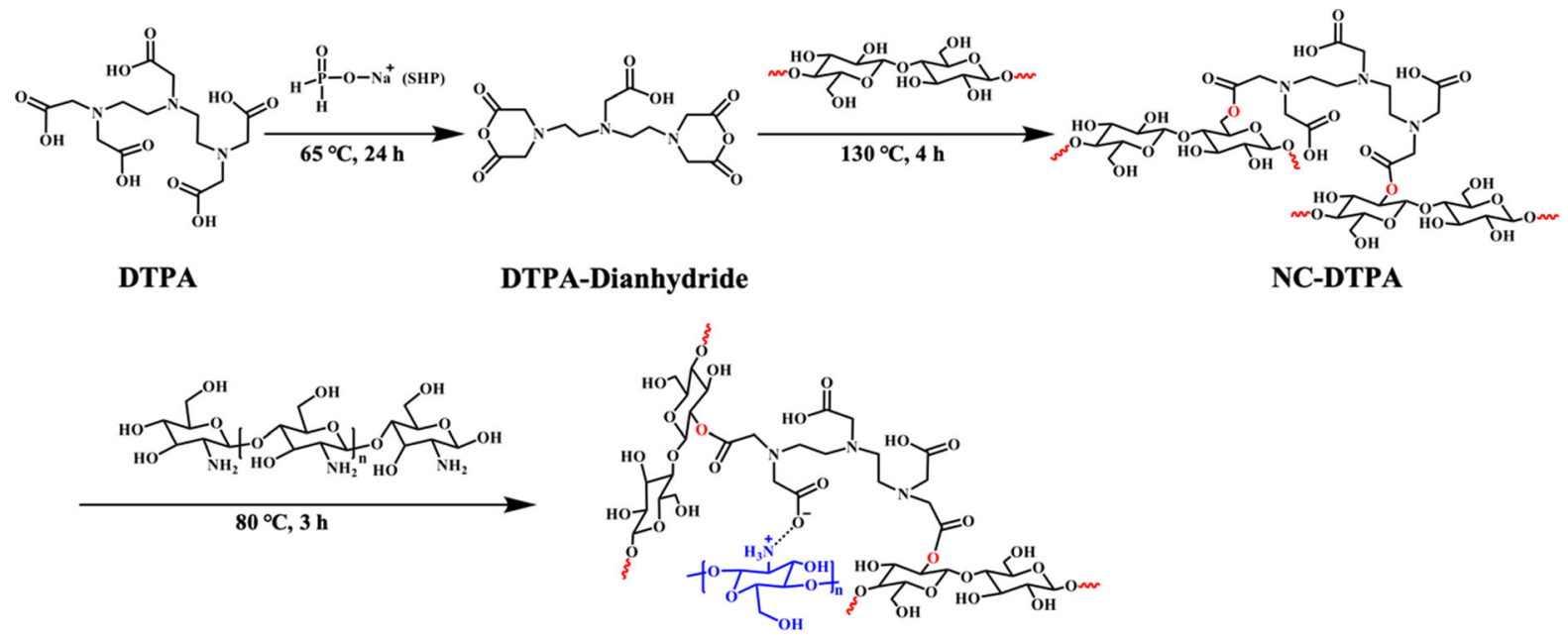

\section{NC-DTPA-CS}

Fig. 1 Chemical reaction and structure of NC-DTPA-CS

stirred using the fibre standard dissociator (TO75-A, Xianyang Tongda Light Industrial Equipment Co., Ltd., China) at 30,000 rpm for $5 \mathrm{~min}$. This pulp without any additive was used as the control sample.

NC-DTPA-CS $(0.1,0.2,0.3,0.5,1.0,1.5,2.0 \mathrm{wt} \%$, based on dry weight of pulp) were added into the furnish and stirred at the same mixing rate for $5 \mathrm{~min}$. The furnish transferred to a rapid sheet former (GMBH-S95854-0014, FRANK/PTI, Germany), in which the handsheets were made according to the TAPPI T 205 sp-02 test method. The NC was also added to the OCC fibre suspension in the same proportions for comparison and the sheet preparation was made according to the above steps. The base weights of handsheets were set at $60 \mathrm{~g} / \mathrm{m}^{2}$. The final dried handsheets were then stored at a humidity of $45 \%$ and a temperature of $25^{\circ} \mathrm{C}$. The experimental flow diagram is shown in Fig. 2.

\section{Characterizations}

\section{Tensile strength test}

The tensile strength of OCC handsheets was tested using the L\&W tensile strength tester (Code 066, L\&W Sweden, Sweden) according to the TAPPI T 494 method. The samples were cut from the handsheets with a rectangular dimension of $15 \mathrm{~mm} \times 180 \mathrm{~mm}$ and tested with a tensile rate of $10 \mathrm{~mm} / \mathrm{min}$. 10 specimens were tested in each group and the average value was taken as the final result. The Tensile index was calculated by dividing the tensile strength $(\mathrm{N} / \mathrm{m})$ by basis weight $\left(\mathrm{g} / \mathrm{m}^{2}\right)$.

\section{Tear strength test}

Tear strength of OCC pulp handsheets was tested using L\&W tear tester (Code 009, L\&W Sweden, Sweden) according to TAPPI T 414 method. The samples were cut from the handsheets with a rectangular dimension of $63 \mathrm{~mm} \times 75 \mathrm{~mm}$. 5 test pieces were cut in each direction and tested, and the average value was taken as the final result. The tear index $\left(\mathrm{mN} \cdot \mathrm{m}^{2} / \mathrm{g}\right)$ was calculated by dividing the tear strength $(\mathrm{mN})$ by basis weight $\left(\mathrm{g} / \mathrm{m}^{2}\right)$.

\section{Burst strength test}

The burst strength of OCC pulp handsheets was tested using the L\&W paperboard bursting tester (Code180, L\&W Sweden, Sweden) according to the TAPPI T 403 method. The dimension of samples was $70 \mathrm{~mm} \times$ $70 \mathrm{~mm}$. 10 valid data were obtained on each side and the average value was taken as the final result. The burst index $\left(\mathrm{kPa} \cdot \mathrm{m}^{2} / \mathrm{g}\right)$ was calculated by dividing the burst strength $(\mathrm{kPa})$ by basis weight $\left(\mathrm{g} / \mathrm{m}^{2}\right)$. 


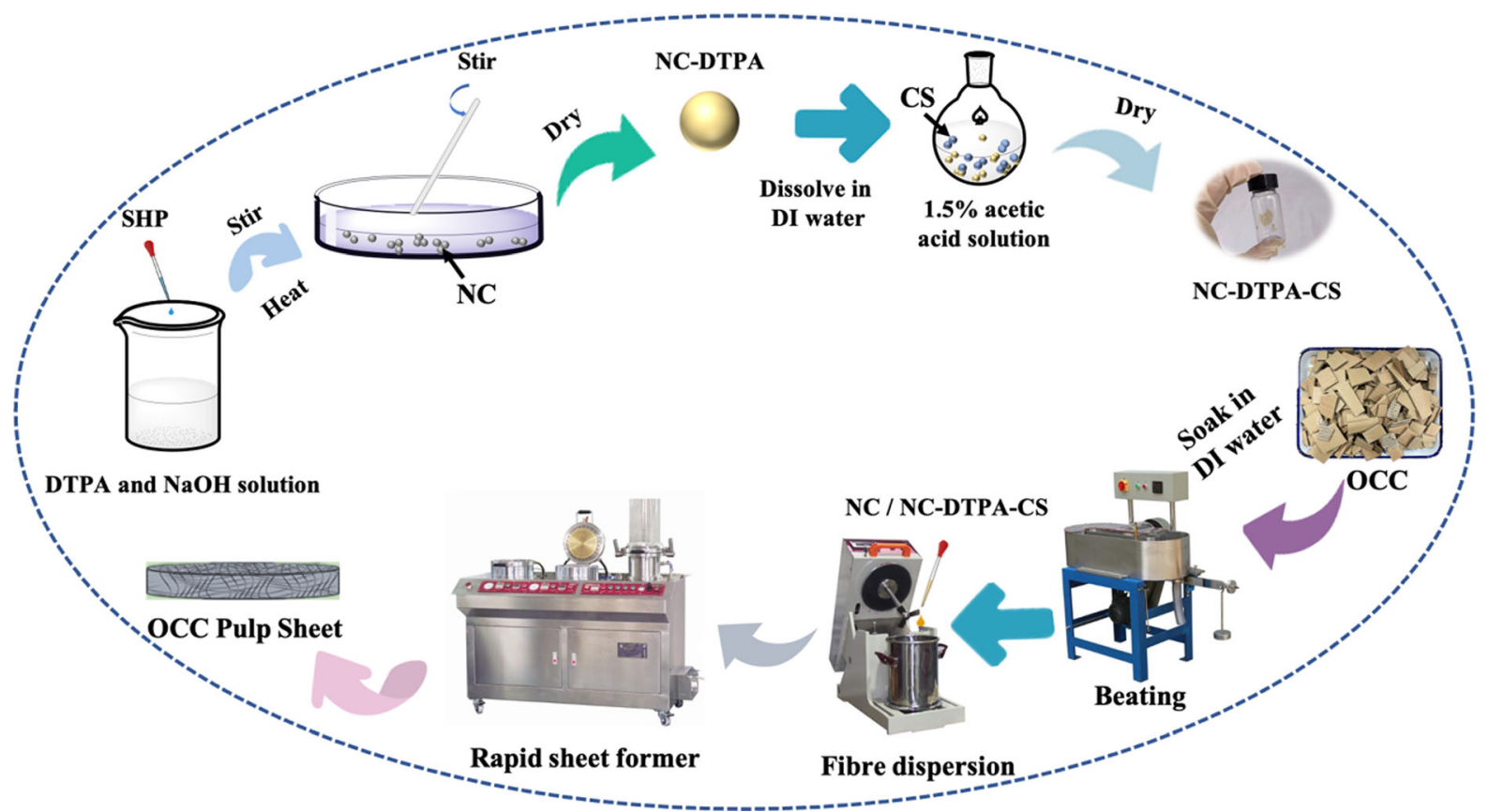

Fig. 2 Schematic diagram of NC-DTPA-CS and paper preparation process

\section{Air permeability test}

The air permeability of OCC pulp handsheets was tested using the paper and board air permeability tester (J-TQY10, Sichuan Changjiang Paper Instrument Co., China) according to the TAPPI T 460 method. $50 \mathrm{~mm}$ $\times 50 \mathrm{~mm}$ samples were used to cover the lower probe of the instrument. Each test sample was measured three times on both sides and the average taken as the final result.

\section{Tensile energy absorption}

Tensile energy absorption (TEA) is a comprehensive function of handsheet strength and elongation, which is an indicator of handsheet toughness. The TEA of OCC handsheets was tested using the L\&W tensile strength tester (Code 066, L\&W Sweden, Sweden) according to the TAPPI T 494 method. Dimension of the samples as $15 \mathrm{~mm} \times 180 \mathrm{~mm}$. 10 specimens were tested in each group and the average value was taken as the final result.

\section{Drainage performance}

The drainage performance is assessed by the drainage time of the OCC pulp containing NC as well as NCDTPA-CS additives according to the TAPPI $\mathrm{T} 221$ om-93 method. The drainage time was obtained at the same time when the sheets are formed with the standard apparatus. Each group of three specimens was tested and the average value was taken as the final result.

\section{FTIR analysis}

Dried handsheets, namely NC (F1), NC-DTPA (F2), NC-DTPA-CS (F3), OCC pulp sheet (F4), OCC-NCDTPA-CS pulp sheet (F5), of 1-2 mg mixed with $100 \mathrm{mg}$ of potassium bromide were scraped and ground well with a razor blade, placed in a mold and pressed at $15 \mathrm{MPa}$ pressure for $2 \mathrm{~min}$ to produce FTIR samples. The FTIR spectra were measured with Fourier transform infrared spectroscopy (Nicolet 380, American Thermoelectric Corporation, USA). Test conditions: resolution $4 \mathrm{~cm}^{-1}, 32$ scans, scan range $4000-400 \mathrm{~cm}^{-1}$. 
Thermal gravimetric analysis (TGA)

The thermal stability of the NC, NC-DTPA, NCDTPA-CS, OCC pulp sheet, OCC-NC-DTPA-CS pulp sheet were determined by taking $6 \mathrm{mg}$ of dried handsheets samples into the DSC simultaneous thermal analyzer (STA449C, NETZSCH Germany Ltd., Germany). Test conditions: nitrogen atmosphere, scanning temperature $25 \sim 800{ }^{\circ} \mathrm{C}$, temperature rise rate $10{ }^{\circ} \mathrm{C} / \mathrm{min}$.

\section{Scanning electron microscope (SEM)}

Scanning electron microscopy was performed on OCC pulp handsheets treated with NC-DTPA-CS derivatives. The pre-prepared handsheets samples were sprayed with gold using a vacuum ion sputtering instrument (JFC-1600, JEOL Corporation, Japan). The structures were then observed and photographed using a Hitachi cold field emission scanning electron microscope (SU 8010, Ko Min International Trade Co., China).

\section{Transmission electron microscopy ( TEM)}

The suspension of dispersed NC (1 wt $\%)$ was dropped onto a copper mesh coated with a porous carbon film and stained with phosphotungstic acid (2 wt $\%)$. The samples were dried at room temperature for $24 \mathrm{~h}$ and the morphology of the NC was tested by TEM (HRTEM, JEOL JEM-2100, Janpan) at an accelerating voltage of $100 \mathrm{KV}$ and a resolution of $0.2 \mathrm{~nm}$.

\section{$X$-ray diffraction $(X R D)$}

The freeze-dried NC samples were ground to a powder and analysed for crystallinity by X-ray diffraction (Bruker D8, Bragg-Brentano Geometry, USA). The specimens were irradiated with $\mathrm{CuK} \alpha$ radiation at the wave length $\lambda=1.5406 \AA$ at $40 \mathrm{kV}$ and $40 \mathrm{~mA}$ in the range $2 \theta=5^{\circ}-50^{\circ}$ with a scanning speed of $5 \% \mathrm{~min}$.

The Crystallinity index (CrI) was evaluated using the following equation (Segal et al. 1959):

$C r I=\frac{I_{200}-I_{a m}}{I_{200}} \times 100 \%$ where $I_{200}$ is the diffraction intensity of the (200) lattice plane in type I cellulose and $I_{a m}$ is the diffraction intensity of the non-crystalline region at the minimum in the intensity near $18^{\circ}$.

Degree of polymerization $(D P)$ and degree of acetylation (DA)

The DP of CS was calculated by dividing the viscosity average molecular weight by $161 \mathrm{~g} / \mathrm{mol}$, which is the molecular weight of the chitosan repeat unit. The DA of CS was calculated according to the following equation (Kou et al. 2021).

$D A=100 \%-D D$

Where, $D A$ is the degree of acetylation (the mole fraction of $\mathrm{N}$-acetylated repeating units) and DD is the degree of deacetylation (the percentage of repeating units of $\beta-1,4-\mathrm{D}$-glucosamine in polysaccharides).

\section{Results and discussion}

$\mathrm{NC}$ and CS characterization

The TEM nanogram is shown in Fig. 3a. Careful measurements summarized that the $\mathrm{NC}$ has a length of $650 \mathrm{~nm}$, width of $10 \mathrm{~nm}$ and length-to-width ratio of 65 . Figure $3 b$ shows the XRD diffraction patterns of the NC. The peaks appeared at $2 \theta$ of 15.3, 16.8, 23.0 and $34.9^{\circ}$, which can be attributed to the cellulose type I (French 2014). The crystallinity index of NC can be calculated as $61.85 \%$ according to Eq. (1). The DP of CS can be calculated as 6211. The DA of the CS can be calculated to be in the range of $5-20 \%$ according to Eq. (2).

Surface functional groups

\section{FTIR of NC additives}

The FTIR spectra of NC (F1), NC-DTPA (F2) and NC-DTPA-CS (F3) are shown in Fig. 4. It is apparent that the spectra of F1, F2, and F3 all have a strong absorption peak at $3438 \mathrm{~cm}^{-1}$, which is the superposition of symmetric and asymmetric stretching vibrations from $\mathrm{O}-\mathrm{H}$ or $\mathrm{N}-\mathrm{H}$. The absorption peak at 
(a)

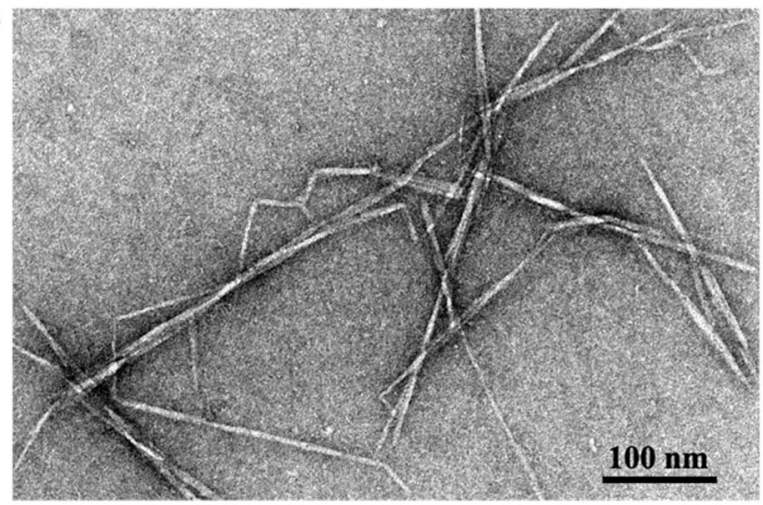

(b)

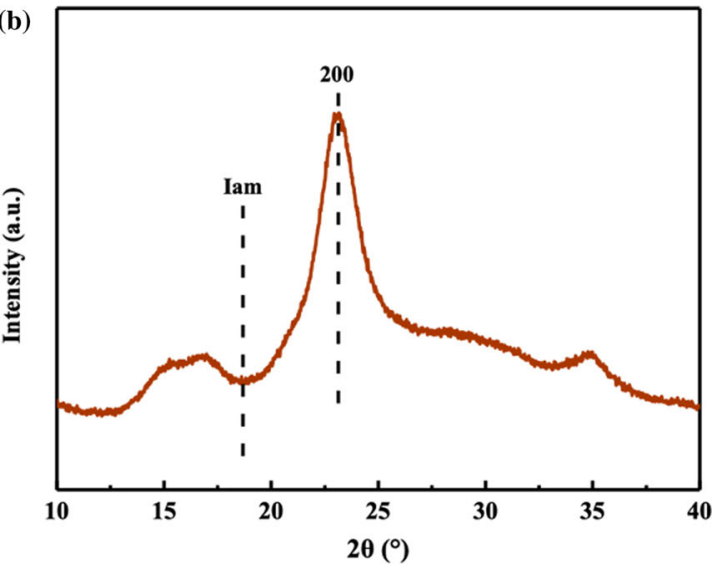

Fig. 3 TEM and XRD image of NC: $a=$ TEM and $b=$ XRD
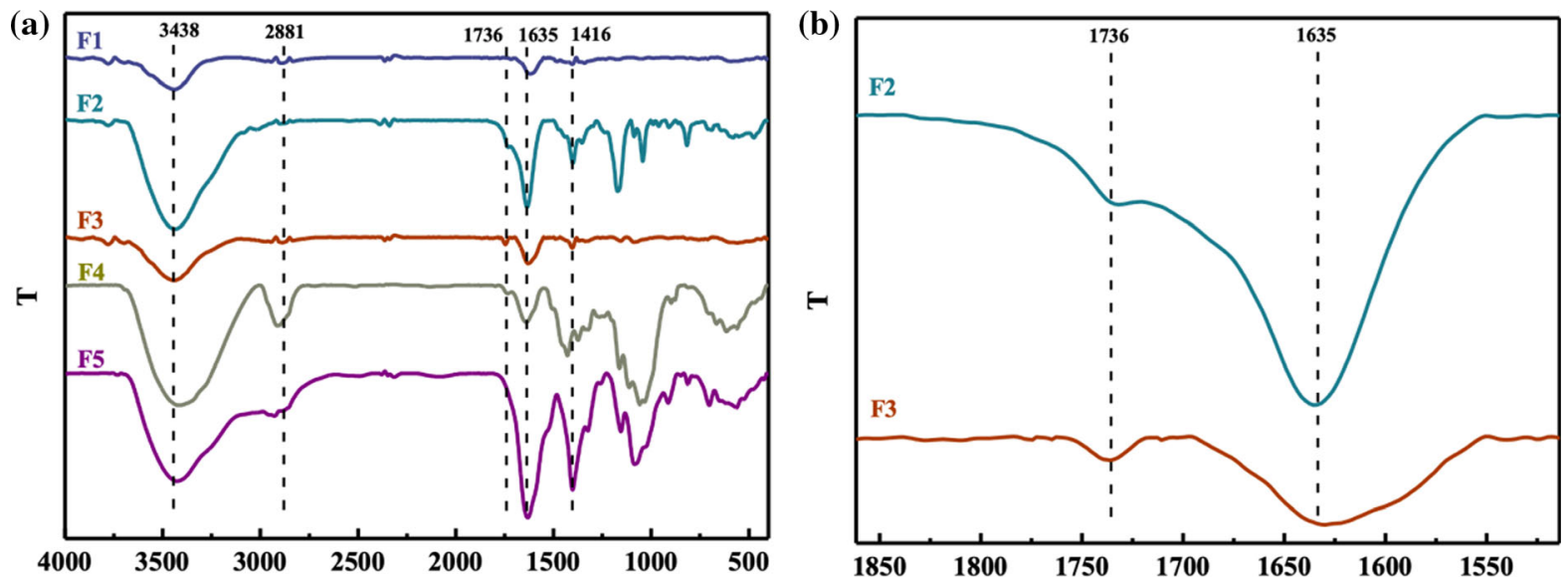

Fig. 4 FTIR Spectra of various handsheets (F1: NC, F2: NC-DTPA, F3: NC-DTPA-CS, F4: OCC pulp sheet, F5: OCC-NC-DTPA-CS pulp sheet)

$1635 \mathrm{~cm}^{-1}$ is attributed to DTPA by the $\mathrm{C}=\mathrm{O}$ stretching vibration and the bending vibration of $\mathrm{N}-\mathrm{H}$. It can be seen that the F1 has no absorption peak at $1700-1800 \mathrm{~cm}^{-1}$, indicating that there is no carbonyl group in the NC. However, there was an absorption peak at $1736 \mathrm{~cm}^{-1}$ in the spectrum of $\mathrm{F} 2$ (Fig. 4a) and this peak refers to the $\mathrm{C}=\mathrm{O}$ double bond stretching vibration absorption peak in the ester group, indicating that the esterification reaction between $\mathrm{NC}$ and DTPA occurred and NC was successfully chelated to DTPA (Salam et al. 2010). The dehydration of DTPA catalyzed by sodium hypophosphite (SHP) generates DTPA dianhydride and the hydroxyl group of the reactive group on the surface of NC may undergo esterification with DTPA dianhydride. The spectrum of F3 shows an absorption peak at
$1416 \mathrm{~cm}^{-1}$ attributed to the C-N stretching vibration absorption peak. There is an absorption peak at $1635 \mathrm{~cm}^{-1}$ attributed to N-H bending vibration absorption peak (Fig. 4b).

\section{FTIR of modified OCC paper}

The FTIR Spectra of OCC pulp sheet (F4) and OCCNC-DTPA-CS pulp sheet (F5) are shown in Fig. 4. It is apparent that the spectra of F4 and F5 all have a strong absorption peak at $3438 \mathrm{~cm}^{-1}$ which may be attributed to the hydroxyl group on the OCC pulp sheet as well as the OCC pulp sheet treated with NC-DTPACS derivative (Fig. 4a). Compared to the control OCC pulp sheet (F4), the NC-DTPA-CS derivative treated 
sheet has a smaller absorption peak at $3438 \mathrm{~cm}^{-1}$ which may be due to the chemical bonding of a large number of hydroxyl groups on the OCC pulp sheet with the reactive groups such as hydroxyl, carboxyl and amino groups on the NC-DTPA-CS derivative. The control OCC pulp sheet (F4) and OCC-NCDTPA-CS pulp sheet (F5) have an absorption peak at $2881 \mathrm{~cm}^{-1}$, which is attributed the stretching vibration of $\mathrm{C}-\mathrm{H}$ in the pulp or in the additives. An absorption peak with high intensity at $1635 \mathrm{~cm}^{-1}$ was attributed to the complexation reaction of the NCDTPA-CS derivative with the OCC pulp after incorporation into the OCC pulp matrix and drying at 105 ${ }^{\circ} \mathrm{C}$, which increases the intensity of this amide band compared to the NC-DTPA-CS derivative. An absorption peak with high intensity at $1635 \mathrm{~cm}^{-1}$ is attributed to the amide group in the NC-DTPA-CS (F3) derivative itself and the amide reaction of the NCDTPA-CS derivative with the hydroxyl group on the OCC pulp after incorporation into the OCC pulp matrix by drying at $105^{\circ} \mathrm{C}$, which leads to a significant increase in the intensity of the amide band. It is further illustrated that the polyelectrolyte complexes interacting between the carboxyl group of NC-DTPA and the amino group of CS may be converted into amide bonds when the NC-DTPA-CS derivatives were incorporated into the OCC pulp matrix.

\section{Thermal behaviour}

\section{Thermal behaviour of $\mathrm{NC}$ additives}

The thermogravimetric analyses of NC, NC-DTPA, and NC-DTPA-CS are given in Fig. 5a. Their thermogravimetric behavior was evaluated at a heating rate of $10^{\circ} \mathrm{C} / \mathrm{min}$ under nitrogen. It can be seen that the thermal decomposition of the three samples, namely NC, NC-DTPA, and NC-DTPA-CS, can be divided into four main stages. The first stage is from room temperature to $100{ }^{\circ} \mathrm{C}$, which is mainly the stage of removal of certain volatile groups, the main component of which is water. The second stage was from 100 ${ }^{\circ} \mathrm{C}$ to around $200{ }^{\circ} \mathrm{C}$. The sample mass was either constant or modest decrease depending on the materials, where NC-DTPA lost more weight than both NC and NC-DTPA-CS, and this may be due to the fact that DTPA has a lower degradation temperature than both $\mathrm{NC}$ as well as CS. The third stage is from $200{ }^{\circ} \mathrm{C}$ to $400{ }^{\circ} \mathrm{C}$. The significant decomposition and rapid weight loss took place, caused by the decomposition, oxidation and combustion of the sample components. The differential thermal thermogravimetric analysis (DTG) of the three samples of NC, NC-DTPA, and NC-DTPA-CS can be further scrutinized as a decomposition rate (Fig. 5b). It can be seen that the weight loss peak of $\mathrm{NC}$ was at $318{ }^{\circ} \mathrm{C}$ and the maximum thermal decomposition rate was reached at this temperature. The maximum thermal decomposition rate was reached at $208{ }^{\circ} \mathrm{C}$ for NC-DTPA and at 203 ${ }^{\circ} \mathrm{C}$ for NC-DTPA-CS. The specific thermal decomposition is shown in Table 1. The fourth stage is from $400{ }^{\circ} \mathrm{C}$ to $500{ }^{\circ} \mathrm{C}$, where the sample is further decomposed and gradually reaches weight loss equilibrium.

While the maximum weight loss temperature of all $\mathrm{NC}$ derivative additives decreases compared to that of $\mathrm{NC}$, the residual mass for the former is significantly higher than that for the latter when heated to $500{ }^{\circ} \mathrm{C}$. This may be due to the lower degradation temperature of the NC modifiers, which are attached to the NC surface through ester bonds (Ferrer et al. 2012). As can be seen from Table 1, the melting temperatures for the $\mathrm{NC}$ derivative additives are elevated, which may be due to the robustness of the chemical structure resulted from the increased hydrogen bonding and higher molecular organization obtained by cross-linking. The introduction of carbonyl group after the modification of NC by esterification reaction may lead to an increase in the number of intermolecular hydrogen bonds, which makes the crosslinking between NC and DTPA molecules more stable. The NC-DTPA grafted with CS is in the form of ionic bonds and more hydrogen bonds could be formed. Therefore, the melting temperature of $\mathrm{NC}$ derivative additives is gradually increasing. $\mathrm{NC}$ has the highest thermal stability with modest weight loss rate. This is due to the introduction of substituents such as carbonyl and hydroxyl groups on the surface of $\mathrm{NC}$, which destroys the structure of $\mathrm{NC}$ and makes $\mathrm{NC}$ derivative additives less stable than NC

The maximum weight loss temperature of NCDTPA-CS additive is lower than that of NC-DTPA. This is because the generation of NC-DTPA-CS is equivalent to the introduction of carbonyl and hydroxyl groups on NC by esterification reaction; the introduction of CS on NC-DTPA by complexation 

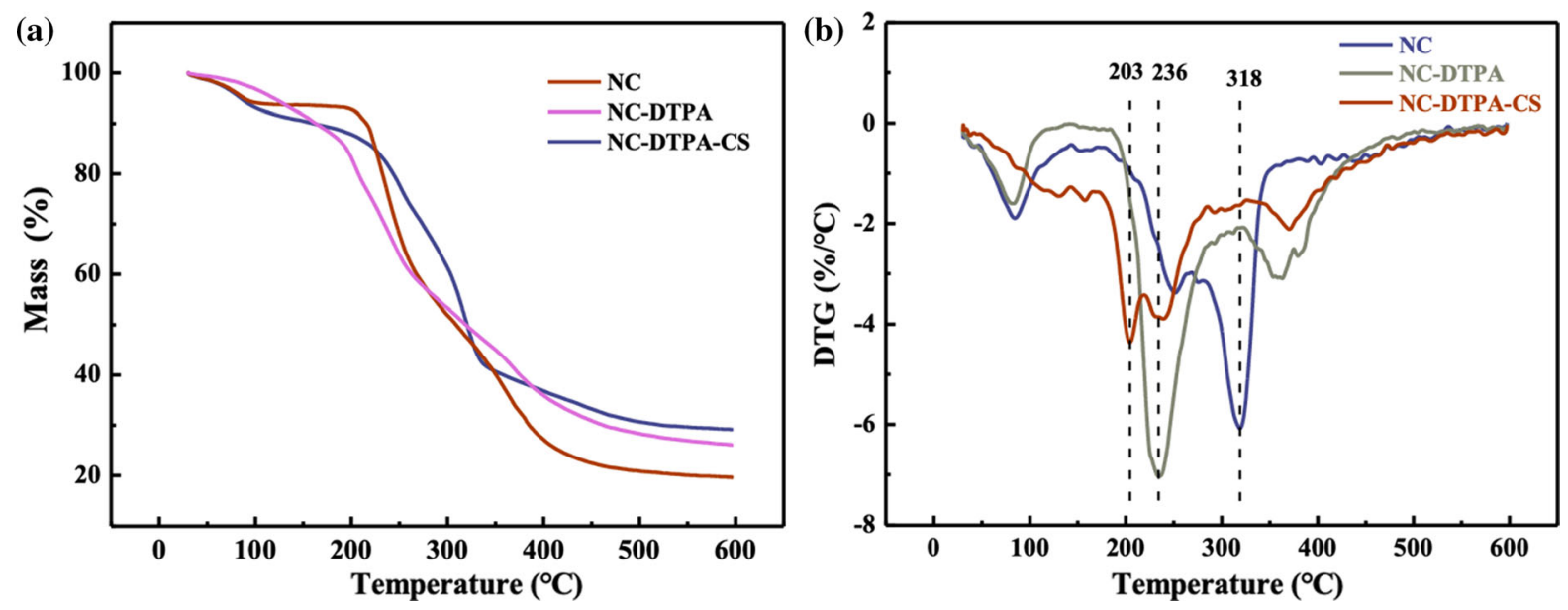

Fig. 5 Schematic diagram of TG and DTG profiles of NC additives

Table.1 Parameters of pyrolytic properties

\begin{tabular}{lllllll}
\hline Samples & $\begin{array}{l}\text { Residuals at } \\
100{ }^{\circ} \mathrm{C}(\%)\end{array}$ & $\begin{array}{l}\text { Residuals at } \\
400{ }^{\circ} \mathrm{C}(\%)\end{array}$ & $\begin{array}{l}\text { Residual carbon at } \\
500{ }^{\circ} \mathrm{C}(\%)\end{array}$ & $\begin{array}{l}\text { Start weight loss } \\
\text { temperature }\left({ }^{\circ} \mathrm{C}\right)\end{array}$ & $\begin{array}{l}\text { Maximum weight loss } \\
\text { temperature }\left({ }^{\circ} \mathrm{C}\right)\end{array}$ & $\begin{array}{l}\text { DSC melting } \\
\text { point }\left({ }^{\circ} \mathrm{C}\right)\end{array}$ \\
\hline NC & 93.15 & 27.14 & 20.85 & 200 & 318 & 106 \\
NC-DTPA & 96.81 & 35.87 & 28.23 & 180 & 236 & 112 \\
NC- & 93.07 & 36.82 & 31.57 & 188 & 203 & 121 \\
$\quad$ DTPA- & & & & & & \\
CS & & & & & & \\
\hline
\end{tabular}

reaction, which is connected by ionic bonding, the chance of hydrogen bonding generated is reduced and the structure of NC-DTPA may be destroyed, which makes the maximum weight loss temperature of NCDTPA-CS lower

\section{Thermal behavior of NC modified OCC sheet}

The TG profiles of NC-DTPA-CS modified OCC sheet are shown in Fig. 6. It can be seen that the thermal decomposition of the control OCC handsheet and the NC-DTPA-CS derivative-treated handsheet can be divided into four main stages. The first stage is the loss of fibre weight caused by the physical adsorption hydrolysis of fibres in the paper. Water physically adsorbed in the paper is desorbed from room temperature to $105{ }^{\circ} \mathrm{C}$. The nature of the paper remains largely unchanged at this stage. The second stage is almost constant in mass, although the production of small molecule gases and some volatile components may take place. The thermo-gravimetric curve was

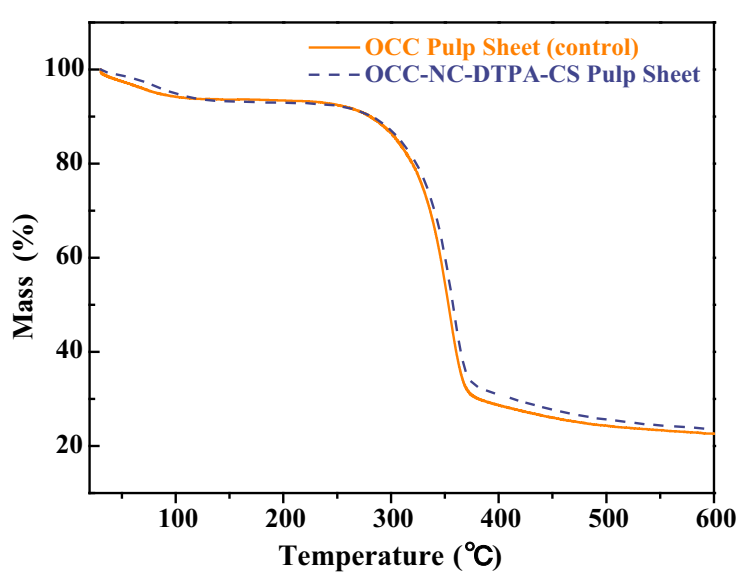

Fig. 6 TG of OCC handsheets

basically horizontal from $105^{\circ} \mathrm{C}$ to $250{ }^{\circ} \mathrm{C}$, which is higher than those of $\mathrm{NC}$ derivative additives themselves. This is because the main components of the OCC pulp sheet have cellulose, and NC has all the properties of cellulose. NC derivatives are based on 
$\mathrm{NC}$ with the introduction of DTPA and CS, which destroy the structure of $\mathrm{NC}$ making its derivatives less thermally stable than $\mathrm{NC}$, therefore the pyrolysis temperature of cellulose at this stage is higher than that of the NC-derived additive itself. The third stage is the main part of the thermal degradation of the sheet, the decomposition of the material is very rapid, the OCC pulp sheet and the sheet treated with NC-DTPA-CS derivatives lose weight sharply, the mass loss is the largest, the glycosidic bonds may open and break to generate some new low molecular weight volatile products. The loss of paper quality is significant from $250{ }^{\circ} \mathrm{C}$ to $380{ }^{\circ} \mathrm{C}$. The fourth stage is the gradual decomposition of the product, causing further weight loss up to almost constant mass. The start weight loss temperature was slightly increased and the initial weight loss mass is reduced even lower in the NCDTPA-CS derivative-treated sample group compared to the control control group, and the temperature at the fastest degradation rate was similar. This may be due to the introduction of substituents such as carbonyl and hydroxyl groups on $\mathrm{NC}$, which increase the chance of hydrogen bonding, the initial degradation weight loss temperature was increased and the temperature at the fastest degradation rate was basically the same. The specific thermal decomposition of the OCC pulp sheet paper and the OCC-NC-DTPA-CS pulp sheet paper were shown in Table 2 . When the temperature reached $600{ }^{\circ} \mathrm{C}$, more residues remained in the sample group modified with NC-DTPA-CS additives, which may be due to the cross-linking of NC-DTPA-CS with pulp fibres.
Strength enhancement of recycled OCC based paper with nanocellulose derivative additives

In packaging paper applications, the paper substrate requires sufficient resistance to external stress to ensure that it does not break easily, which is generally attributable to the adequate development of hydrogen bonds at the molecular level in addition to the fibre strength itself, and also depends on the number and area of bonding sites, which are closely related to the fibre morphology of fibres. Unfortunately, fibres undergo irreversible damage during secondary fibre recycling and without enhancement, this damage eventually affects the mechanical properties of the paper. An enhancement should and could be carried out for an effective recycling and quality paper pulp (Fig. 7). It can be seen that the mechanical properties of the paper could be improved significantly with $\mathrm{NC}$ based additives studied. The burst index of the handsheets with the addition of NC and NC-DTPACS is shown in Fig. 7a. The burst index of handsheets sharply increased by $8.48 \%$ with an addition of $0.1 \%$ NC-DTPA-CS and then gradually increased from $1.612 \mathrm{kPa} \cdot \mathrm{m}^{2} / \mathrm{g}$ to $2.03 \mathrm{kPa} \cdot \mathrm{m}^{2} / \mathrm{g}$, when NC-DTPA$\mathrm{NC}$ increased from 0.1 to $0.3 \%$. However, a continuous increase of additive did not result in an increase rather remained at about $2.00 \mathrm{kPa} \cdot \mathrm{m}^{2} / \mathrm{g}$ when the additive increased from 0.3 to $2 \%$. There was a similar trend of change in the burst index for the addition of $\mathrm{NC}$ additive though with much lower magnitude. The reactive groups on NC and NC-DTPA-CS can produce hydrogen bonding with hydroxyl groups on pulp fibres, increasing the number and area of bonding points between pulp fibres, which could increase the bonding strength between fibres, and therefore the burst index of paper increases. Because there are more reactive groups on NC-DTPA-CS than $\mathrm{NC}$, the number and area of its bonding points with pulp fibres will be higher, leading to greater burst index for NC-

Table.2 Pyrolysis characteristic parameters of OCC handsheets

\begin{tabular}{llll}
\hline Samples & $\begin{array}{l}\text { Start weight loss temperature } \\
\left({ }^{\circ} \mathrm{C}\right)\end{array}$ & $\begin{array}{l}\text { Maximum weight loss temperature } \\
\left({ }^{\circ} \mathrm{C}\right)\end{array}$ & $\begin{array}{l}\text { Residual carbon at 600 } \\
{ }^{\circ} \mathrm{C}(\%)\end{array}$ \\
\hline OCC pulp sheet (control) & 251 & 328 & 19.54 \\
$\begin{array}{l}\text { OCC-NC-DTPA-CS pulp } \\
\text { sheet }\end{array}$ & 254 & 320 & 23.57 \\
\hline
\end{tabular}



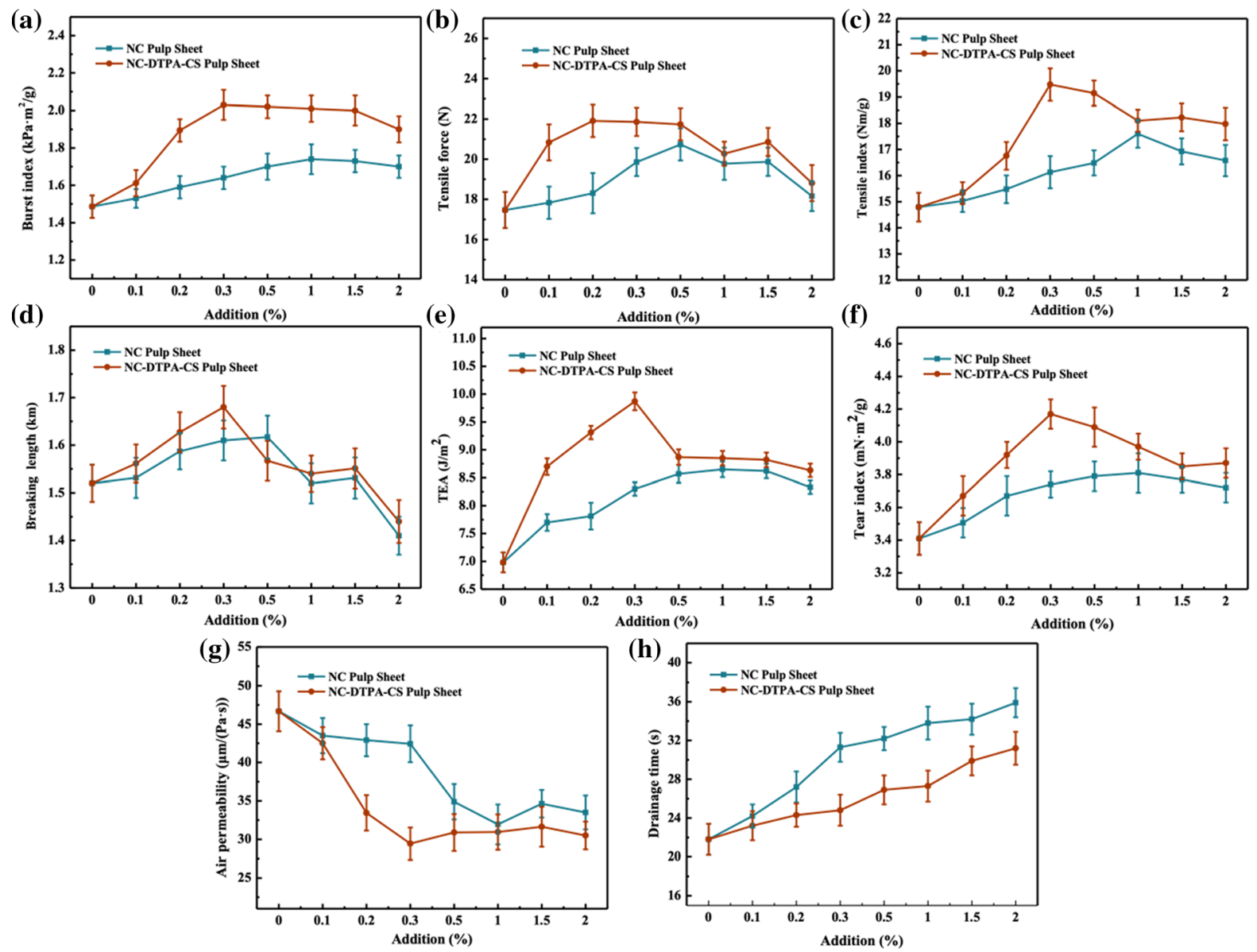

Fig. 7 Physical properties of paper with NC and NC-DTPA-CS content a Burst index, b Tensile force, $\mathbf{c}$ Tensile index, $\mathbf{d}$ Breaking length, e TEA, $\mathbf{f}$ Tear index, $\mathbf{g}$ Air permeability, $\mathbf{h}$ Drainage time.

DTPA-CS than NC enhanced fibres. The tensile force of the handsheets with the addition of NC and NCDTPA-CS is shown in Fig. 7b. With the increase in the amount of NC and NC-DTPA-CS added, the tensile force of the handsheets shows a trend of rising and then decreasing, because a certain amount of $\mathrm{NC}$ and NC-DTPA-CS can cross-link with the pulp fibres. The tensile force is strengthened during the curing and drying process of the paper, and the bonding between the fibres is increased, thus increasing the tension resistance of the paper. Tensile strength of paper and paperboard is one of the parameters that determine their applications. The main factors that affect the tensile strength of paper include the bond strength between fibres, the strength of the fibres themselves, and the interweaving between fibres (Ferrer et al. 2012). The tensile index of the NC and NC-DTPA-CS enhanced handsheets is given in Fig. 7c. The tensile index both increased and then decreased as the amount of NC and NC-DTPA-CS increased. When NCDTPA-CS was added at $0.3 \%$, the tensile index reached $19.47 \mathrm{Nm} / \mathrm{g}$, an increase of $31.68 \%$ compared with the control the OCC handsheets. This may be due to the fact that the structural molecules of NC-DTPACS derivatives contain basic amino groups, which could generate positive charges in slightly acidic media and may form covalent or ionic bonds with negatively charged fibres in pulp fibres during the papermaking process (Mucha and Miśkiewicz 2000). The DTPA in NC-DTPA-CS derivatives is rich in free carboxyl groups, which could also form ionic bonds with the fibres on the surface of pulp fibres and increase the relative bonding area of the fibre facultative (Duker and Lindstrom 2008). The increase for NC-DTPA-CS modified fibres were significantly higher compared to that for the same content of NC. 
This is probably due to the high surface area/volume ratio of the $\mathrm{NC}$ derivatives and the relatively strong chemical bonding between the OCC pulp fibres through the large number of carboxyl and amino groups on the derivatives. $\mathrm{NC}$ and their derivatives can become very thin films and distributed in the fibres during the drying and heating of the paper. Therefore, by increasing the generation of contact area, more hydrogen bonds can be formed between the fibres and the NC derivatives, and there are more opportunities for freely bonding of the fibre hydroxyl groups. The free carboxyl groups of $\mathrm{NC}$ also contribute to interfibre bonding, thus improving paper strength (Bernabe et al. 2005). Therefore, the increase in tensile index can be attributed to the carboxyl, amino, and hydroxyl groups, increasing the inter-fibre bonding area as well as the number of bonds during the paper forming process. When the additives exceed $0.3 \%$, the bonding of NC-DTPA-CS with pulp fibres may reach saturation, and the number of bonding and bonding area reaches the limit. The changes of paper breaking length with the addition of NC and NC-DTPA-CS are shown in Fig. 7d. With the increase of NC and NCDTPA-CS, the breaking length increased and then levelled off. The addition of $0.3 \%$ of NC-DTPA-CS resulted in a significant increase of $10.53 \%$ in the breaking length of the handsheet. However, when the additive was increased from 0.3 to $2 \%$, the continued increase of the additive did not result in an increase but a gradual decrease from $1.68 \mathrm{~km}$ to $1.56 \mathrm{~km}$. A similar trend in breaking length was observed with the addition of NC additive, but the magnitude was much smaller and the fracture length reached a maximum of $1.62 \mathrm{~km}$ when the addition of $\mathrm{NC}$ additive was to reach $1 \%$.

Tensile energy absorption (TEA) is a paper physical property index that combines tensile strength and tensile rate (strain) into one consideration, which can indirectly reflect the strength and toughness of packaging paper or recycled paper. It can be seen that $\mathrm{NC}$ and NC-DTPA-CS modifications resulted in significant effect on the TEA (Fig. 7e). When the stretch rate is increased or the tensile strength is increased, the tensile absorption energy of the paper is increased. An addition of $0.3 \%$ NC-DTPA-CS gave rise to about $41.40 \%$ increase in TEA, but further increase in additives resulted in a decrease in TEA. NC modification has a much modest effect on TEA, which gradually increases with the increase of NC and then level off after $0.5 \%$ addition. This may be because the addition of NC and NC-DTPA-CS makes the interfibre bond stronger, which leads to an increase in the $\mathrm{f}$ breaking length. The changes in tear index of the OCC handsheet with the addition of NC and NC-DTPA-CS are given in Fig. $7 \mathrm{f}$. It is evident that the tear index of papers increases and reached a maximum at $0.3 \% \mathrm{NC}$ DTPA-CS and at $1 \% \mathrm{NC}$ additions respectively. Paper whiteness refers to the ability of the paper to be fully reflected by light irradiation, and the higher the whiteness of the paper, the more its surface can make the characteristic of the ink color accurately (Bristow 1994).

The air permeability of the paper did not change significantly with the increase in the content of the additive NC-DTPA-CS (Fig. 7g) It is interesting that the air permeability of the developed paper decreased and then levelled off with the additive content. When the content of NC-DTPA-CS was $0.3 \%$, the paper air permeability showed a minimum value of $29.44 \mu \mathrm{m} /$ $(\mathrm{Pa} \cdot \mathrm{s})$. This means the paper pore structure became smaller and the paper tightness increased, which was attributed to the increase in bonding and networking of fibres, especially fine fibres after NC-DTPA-CS or NC modifications.

The effect of NC and NC-DTPA-CS on the drainage time of OCC pulp was also studied (Fig. 7h). It is apparent that the addition of both $\mathrm{NC}$ and $\mathrm{NC}$ DTPA-CS significantly increased the drainage time of the suspension. The drainage time with $2 \% \mathrm{NC}$ increased by $64.67 \%$ compared to the blank group of OCC pulp suspensions. NC may form a nano-network within the macroscopic fibre network, a potential mechanism for the reduced drainage rate. However, the drainage performance was significantly improved by the use of NC-DTPA-CS, increasing the drainage time by $43.12 \%$ at $2 \%$ concentration compared to the control group.

It can be seen that the values of the physical and mechanical indices investigated decreased when the amount of $\mathrm{NC}$ added exceeded $1 \%$ and when the amount of NC-DTPA-CS added exceeded $0.3 \%$. This is due to the fact that as the amount of $\mathrm{NC}$ and $\mathrm{NC}$ DTPA-CS added increases, the interaction between $\mathrm{NC}$ and NC-DTPA-CS itself becomes more and more important, which together with the fact that the effective charge and hydroxyl groups on the pulp fibre surface become less and less, resulting in a 
gradual decrease in the interaction between $\mathrm{NC}$ and fibre and between NC-DTPA-CS and fibre, so that the performance of the OCC handsheets decreases above a certain amount. Another important point is the effect of higher amounts of NC and NC-DTPA-CS, which makes it more difficult to disperse them evenly due to the unfavourable formation of the handsheets, which results in a downward trend in its properties.

OCC refers to pulp with fibres that have passed through at least two recycling processes, which are shorter and weaker than the original fibres, resulting in poor quality in terms of paper strength. OCC contains a large amount of anionic trash and more fine fibres, where the presence of these anions prevents the bonding between pulp fibres (Zhao et al. 2014). It is obvious that the recycled fibres can be used effectively by using a retention aid or reinforcing agents, i.e. NC or NC-DTPA-CS, which could make the short and fine fibres in OCC form a flocculent form, so that the bonding ability of the short and fine fibres with anions in OCC becomes stronger, and therefore the strength properties of OCC can be improved. The hydroxyl, carboxyl, amino and other reactive groups on NCDTPA-CS can produce chemical bonding and hydrogen bonding with pulp fibres, and generate stable chemical bonds by curing and heating (Fig. 8a). On the other hand, NC-DTPA-CS can act as a bridge between OCC and anionic waste (Fig. 8b), and some reactive groups on it are suitable for forming agglomerates with anionic waste and fine fibres, which further increases the chances of fibre-fibre and fibre-anion bonding, thereby leading to improved OCC strength properties. This is in agreement with the SEM results.

It is apparent that the effect of the developed NCDTPA-CS on the recycled OCC handsheets was

(a)

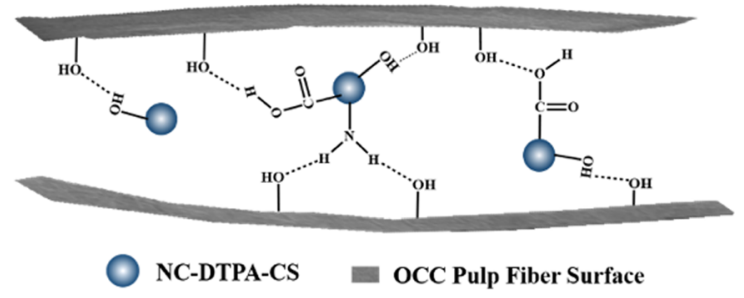

Fig. 8 Schematic of NC-DTPA-CS enhanced OCC paper sheet significant, which is mostly superior to the reinforcements published by previous workers using other additives, e.g. 3\% lignocellulosic nanocellulose (LCNF)/OCC and $1.5 \%$ cationic starch $\left(\mathrm{CS}_{1}\right)+1 \%$ nanosilica (NS)/OCC achieving tensile index improvement of $22 \%$ and $41 \%$ respectively (Yousefhashemi et al. 2019), NC+10\% chitosan nanoparticles (CHNP)/rice straw pulp (RSP) of 26\% (Hassan et al. 2016), $1 \%$ CS/wood pulp (WP) of $21 \%, 0.6 \%$ $\mathrm{CS}_{1}+2 \% \mathrm{NC} / \mathrm{Semi}$-bleached soda bagasse pulp (SBSBP) of 33\%(Tajik et al. 2018)and 0.6\% polyamide epichlorohydrin (PAE)/ polyacrylonitrile (PAN) of 21\% (Zhang et al. 2018). The material used in this paper is OCC, which occupies a major part of the recycling market, and concentration of the $\mathrm{NC}$ DTPA-CS used is very low, but the enhancement of strength properties was significant. The best reinforcement effect was achieved when the NC-DTPA-CS was added at $0.3 \%$. The tensile index increased by $31.64 \%$, the burst index by $22.28 \%$, the tear index by $36.6 \%$, the TEA by $41.4 \%$.

\section{Structure of the enhanced OCC paper}

The SEM images of the paper fibre surface are shown in Fig. 9. It can be seen that the OCC handsheet fibres without NC-DTPA-CS and NC addition were loosely interwoven without tight arrangement; there existed various spaces between the fibres and on the fibre surface, and local splits and irregular sparse morphology (Fig. 9A0). This may be due to the low degree of cross-linking between the fibres and among fibrils on the fibre surface. The fibres with NC and NC-DTPACS addition have a thin film with smooth surface compared with those untreated (Fig. 9(A1-A7), (B1B7)), which may be due to the formation of hydrogen

\section{(b)}

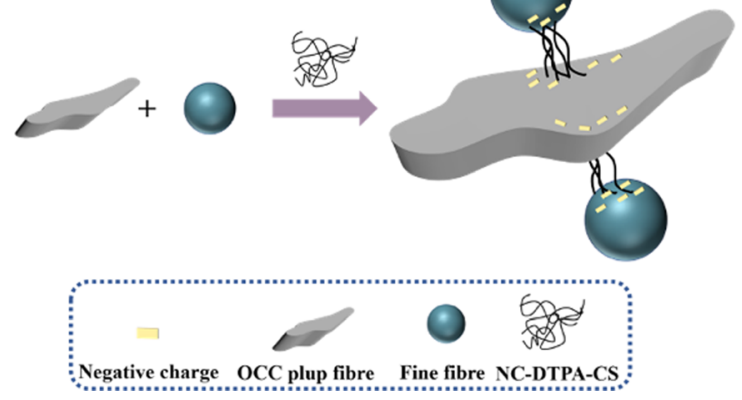




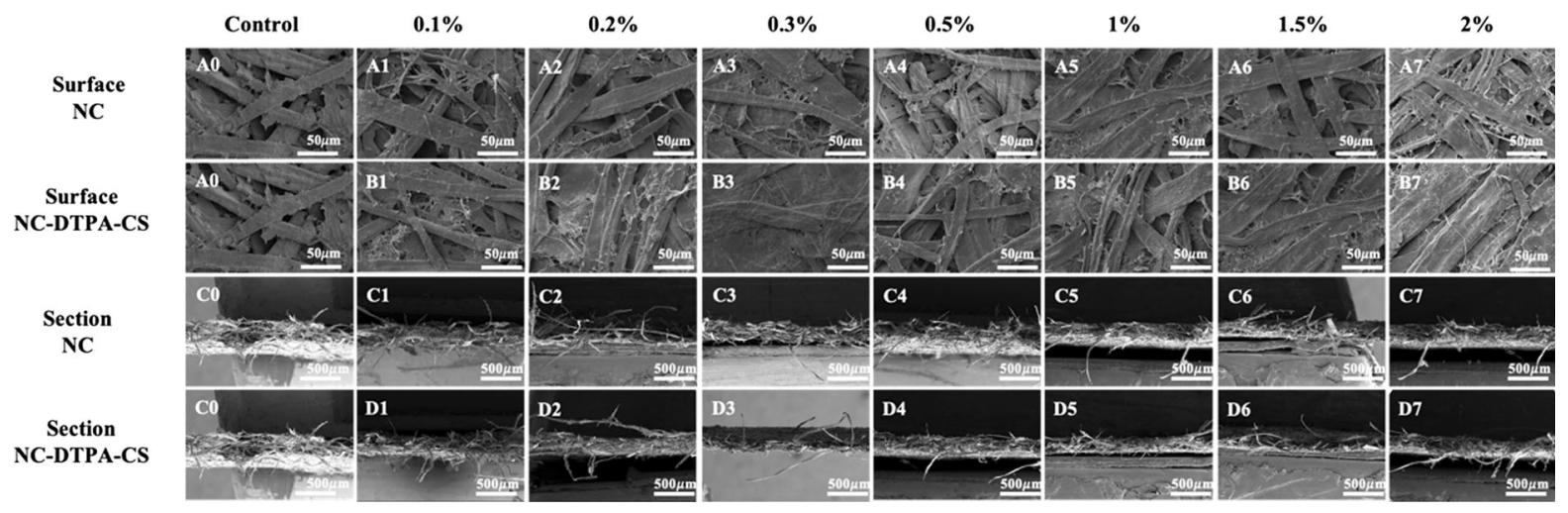

Fig. 9 Morphology of recycled OCC handsheets with different additives: $\mathrm{A} 0$ is the surface; $\mathrm{C} 0$ is the cross section; $\mathrm{A} 1-\mathrm{A} 7$ shows the surfaces with $0.1,0.2,0.3,0.5,1.0,1.5,2.0 \mathrm{wt} \% \mathrm{NC}$ respectively; B1-B7 shows the surfaces with $0.1,0.2,0.3,0.5$, $1.0,1.5,2.0 \mathrm{wt} \%$ NC-DTPA-CS respectively; $\mathrm{C} 1-\mathrm{C} 7$ shows the

bonds between the NC and pulp fibres to make the inter-fibre bond tighter, and the cross-linking phenomenon on the OCC pulp fibres with the NC and NCDTPA-CS additives. While the fibre surface of OCC paper with $1 \%$ NC added (Fig. 9A5) has more complex fibre cross-linking and significantly reduced voids compared to the untreated, the cross-linking between OCC fibres with the addition of NC-DTPACS is much tighter (Fig. 9(B1-B7)), and it can be seen that deposits appear on the fibre surface, with almost no fibre gaps, and the fibres interlock and interpenetrate each other are closely aligned, which are more stable after heat curing.

The SEM images of OCC fibre cross sections show that the fibres in the OCC sections of the control group (Fig. 9C0) were fluffy, disorganized and not compact. However, this gradually changed to neat and compact structures with the addition of NC-DTPA-CS, and the fibres interlocked and interpenetrated each other and arranged closely. It is evident that the surface of paper fibres after the addition of $0.3 \%$ NC-DTPA-CS is flatter and smooth compared to those without treatment (Fig. 9D3). This may be due to the fact that NCDTPA-CS is attached to the pulp fibres and the multifunctional groups on the NC-DTPA-CS derivatives form chemical bonds with the hydroxyl groups on the pulp fibres, which increases the number of fibreto-fibre bonds and the bonding area, thus making the paper structure more compact. A high-strength interpenetrating network structure may also be formed in cross sections with $0.1,0.2,0.3,0.5,1.0,1.5,2.0 \mathrm{wt} \% \mathrm{NC}$ respectively; D1-D7 shows the cross sections with $0.1,0.2,0.3$, $0.5,1.0,1.5,2.0 \mathrm{wt} \%$ NC-DTPA-CS respectively. Note: The specimens in the cross section are the break surface after tensile strength determination

the paper, which improves the bond strength between fibres.

\section{Conclusions}

(1) NC was confirmed by Fourier infrared spectroscopy (FTIR) to produce ester bonds by esterification with DTPA and amide bonds by amide reaction with CS to successfully formulate a novel paper reinforcing agent, NC-DTPACS.

(2) NC-DTPA-CS has been successfully applied to recycled OCC pulp as a reinforcing agent with rapid paper forming and drying.

(3) NC-DTPA-CS significantly improved various physical properties of used OCC handsheet and enhanced the recyclability of OCC pulps; NCDTPA-CS could react with the hydroxyl groups of pulp fibres to form chemical bonds that were attached to the paper, increasing the crosslinking between fibres as well as the bonding area. The surface of paper fibres modified with NC-DTPA-CS was smooth with interpenetrating interlacing fibres and compact structure. The paper modified with NC-DTPA-CS exhibited higher thermal stability than that of untreated and higher mass retention when the temperature reached $600{ }^{\circ} \mathrm{C}$ partly due to the cross-linking of NC-DTPA-CS with the pulp fibres. The 
optimal addition of NC-DTPA-CS at $0.3 \%$ resulted in an increase in the tensile index by $31.64 \%$, tear index by $22.28 \%$, burst index by $36.6 \%$, and air permeability decreased by $36.92 \%$ compared with the untreated recycled OCC handsheets.

Acknowledgments This work was supported by the National Natural Science Foundation of China [Grant number 31971592]; the National Key Scientific Research Project of China [Grant number 2016YFD060070504].

Author contributions Ao Li: Investigation and original draft. Dezhong Xu: Data acquisition. Mengnan Zhang: Investigation. Shengzhong Wu: Methodology. Yu Li: Concept and design. Jiuping Rao: Concept and supervision. Yonghui Zhou: Methodology. Omar Abo Madyan: Concept and review. Weisheng Sun: Concept and review. Mizi Fan: Supervision, review and editing.

\section{Declaration}

Conflict of interest The authors declare that they have no conflict of interest.

Open Access This article is licensed under a Creative Commons Attribution 4.0 International License, which permits use, sharing, adaptation, distribution and reproduction in any medium or format, as long as you give appropriate credit to the original author(s) and the source, provide a link to the Creative Commons licence, and indicate if changes were made. The images or other third party material in this article are included in the article's Creative Commons licence, unless indicated otherwise in a credit line to the material. If material is not included in the article's Creative Commons licence and your intended use is not permitted by statutory regulation or exceeds the permitted use, you will need to obtain permission directly from the copyright holder. To view a copy of this licence, visit http://creativecommons.org/licenses/by/4.0/.

\section{References}

Ahola S, Osterberg M, Laine J (2008) Cellulose nanofibrilsadsorption with poly(amideamine) epichlorohydrin studied by QCM-D and application as a paper strength additive. Cellulose 15:303-314. https://doi.org/10.1007/s10570007-9167-3

Amini E, Tajvidi M, Gardner DJ, Bousfield DW (2017) Utilization of cellulose nanofibrils as a binder for particleboard manufacture. BioResources 12:4093-4110. https://doi.org/10.15376/biores.12.2.4093-4110

Bernabe P, Peniche C, Arguelles-Monal W (2005) Swelling behavior of chitosan/pectin polyelectrolyte complex membranes. Effect of thermal cross-linking. Polym Bull 55:367-375. https://doi.org/10.1007/s00289-005-0439-5
Bristow JA (1994) The calibration of instruments for the measurement of paper whiteness. Color Res Appl 19:475-483

Dufresne A (2010) Processing of polymer nanocomposites reinforced with polysaccharide nanocrystals. Molecules 15:4111-4128. https://doi.org/10.3390/ molecules 15064111

Duker E, Lindstrom T (2008) On the mechanisms behind the ability of CMC to enhance paper strength. Nord Pulp Paper Res J 23:57-64. https://doi.org/10.3183/npprj-2008-23-01p057-064

Espinosa E, Rol F, Bras J, Rodriguez A (2019) Production of lignocellulose nanofibers from wheat straw by different fibrillation methods. Comparison of its viability in cardboard recycling process. J Clean Prod 239:118083. https:// doi.org/10.1016/j.jclepro.2019.118083

Espinosa E, Tarres Q, Delgado-Aguilar M, Gonzalez I, Mutje P, Rodriguez A (2016) Suitability of wheat straw semichemical pulp for the fabrication of lignocellulosic nanofibres and their application to papermaking slurries. Cellulose 23:837-852. https://doi.org/10.1007/s10570015-0807-8

Ferrer A et al (2012) Effect of residual lignin and heteropolysaccharides in nanofibrillar cellulose and nanopaper from wood fibers. Cellulose 19:2179-2193. https://doi.org/10.1007/s10570-012-9788-z

French $\mathrm{AD}$ (2014) Idealized powder diffraction patterns for cellulose polymorphs. Cellulose 21:885-896. https://doi. org/10.1007/s10570-013-0030-4

French AD (2017) Glucose, not cellobiose, is the repeating unit of cellulose and why that is important. Cellulose 24:4605-4609. https://doi.org/10.1007/s10570-017-14503

French AD (2017) Glucose, not cellobiose, is the repeating unit of cellulose and why that is important. Cellulose 24:4605-4609. https://doi.org/10.1007/s10570-017-14503

French AD (2017) Glucose not cellobiose, is the repeating unit of cellulose and why that is important. Cellulose 24:4605-4609. https://doi.org/10.1007/s10570-017-14503

Gardner DJ, Oporto GS, Mills R, Samir MASA (2008) Adhesion and surface issues in cellulose and nanocellulose. J Adhes Sci Technol 22:545-567. https://doi.org/10.1163/ $156856108 \times 295509$

Hassan EA, Hassan ML, Abou-Zeid RE, El-Wakil NA (2016) Novel nanofibrillated cellulose/chitosan nanoparticles nanocomposites films and their use for paper coating. Ind Crop Prod 93:219-226. https://doi.org/10.1016/j.indcrop. 2015.12.006

He M, Yang G, Cho B-U, Lee YK, Won JM (2017) Effects of addition method and fibrillation degree of cellulose nanofibrils on furnish drainability and paper properties. Cellulose 24:5657-5669. https://doi.org/10.1007/s10570017-1495-3

Holbery JD, Wood DL, Fisher RM (2000) Analysis and characterization of contaminants in OCC recycle furnishes. Tappi J 83:57

Hollertz R, Duran VL, Larsson PA, Wagberg L (2017) Chemically modified cellulose micro- and nanofibrils as paperstrength additives. Cellulose 24:3883-3899. https://doi. org/10.1007/s10570-017-1387-6 
Hubbe MA, Rojas OJ, Lucia LA (2015) Green modification of surface characteristics of cellulosic materials at the molecular or nano scale: a review. BioResources 10:6095-6206

Hubbe MA, Tayeb P, Joyce M, Tyagi P, Kehoe M, Dimic-Misic K, Pal L (2017) Rheology of nanocellulose-rich aqueous suspensions: a review. BioResources 12:9556-9661. https://doi.org/10.15376/biores.12.4.Hubbe

Jiang L et al (2015) Layer-by-layer immobilization of quaternized carboxymethyl chitosan/organic rectorite and alginate onto nanofibrous mats and their antibacterial application. Carbohydr Polym 121:428-435. https://doi. org/10.1016/j.carbpol.2014.12.069

Kalia S, Dufresne A, Cherian BM, Kaith BS, Averous L, Njuguna J, Nassiopoulos E (2011) Cellulose-based bio- and nanocomposites: a review. Int $J$ Polym Sci 2011:2341-2348. https://doi.org/10.1155/2011/837875

Khalil HPSA, Davoudpour Y, Islam MN, Mustapha A, Sudesh K, Dungani R, Jawaid M (2014) Production and modification of nanofibrillated cellulose using various mechanical processes: a review. Carbohydr Polym 99:649-665. https://doi.org/10.1016/j.carbpol.2013.08.069

Klemm D et al (2018) Nanocellulose as a natural source for groundbreaking applications in materials science: today's state. Mater Today 21:720-748. https://doi.org/10.1016/j. mattod.2018.02.001

Kou S, Peters LM, Mucalo MR (2021) Chitosan: a review of sources and preparation methods. Int J Biol Macromol 169:85-94. https://doi.org/10.1016/j.ijbiomac.2020.12. 005

Li A et al (2021) Overview of nanocellulose as additives in paper processing and paper products. Nanotechnol Rev 10:264-281. https://doi.org/10.1515/ntrev-2021-0023

Mahfoudhi N, Boufi S (2017) Nanocellulose as a novel nanostructured adsorbent for environmental remediation: a review. Cellulose 24:1171-1197. https://doi.org/10.1007/ s10570-017-1194-0

Mishra RK, Sabu A, Tiwari SK (2018) Materials chemistry and the futurist eco-friendly applications of nanocellulose: status and prospect. J Saudi Chem Soc 22:949-978. https:// doi.org/10.1016/j.jscs.2018.02.005

Mucha M, Miśkiewicz D (2000) Chitosan blends as fillers for paper. J Appl Polym Sci 77:3210-3215

Onur A, Ng A, Gamier G, Batchelor W (2019) The use of cellulose nanofibres to reduce the wet strength polymer quantity for development of cleaner filters. J Clean Prod 215:226-231. https://doi.org/10.1016/j.jclepro.2019.01. 017

Pei A, Malho J-M, Ruokolainen J, Zhou Q, Berglund LA (2011) Strong nanocomposite reinforcement effects in polyurethane elastomer with low volume fraction of cellulose nanocrystals. Macromolecules 44:4422-4427. https://doi. org/10.1021/ma200318k

Poletto M, Pistor V, Zattera AJ (2013) Structural characteristics and thermal properties of native cellulose, vol 2. Cellulose Fundamental Aspects

Rahmaninia M, Khosravani A (2015) Improving the paper recycling process of old corrugated container wastes. Cell Chem Technol 49:203-208
Salam A, Pawlak JJ, Venditti RA, El-tahlawy K (2010) Synthesis and characterization of starch Citrate-Chitosan foam with superior water and saline absorbance properties. Biomacromolecules 11:1453-1459. https://doi.org/10. 1021/bm1000235

Segal L, Creely JJ, Martin A Jr, Conrad C (1959) An empirical method for estimating the degree of crystallinity of native cellulose using the X-ray diffractometer. Text Res J 29:786-794. https://doi.org/10.1177/ 004051755902901003

Sheikhi P, Talaeipour M (2011) Comparison mechanical and chemical treatments on properties of low yield bagasse pulp during recycling. World Acad of Sci, Eng and Tech 57:490-494

Tajik M, Torshizi HJ, Resalati H, Hamzeh Y (2018) Effects of cationic starch in the presence of cellulose nanofibrils on structural, optical and strength properties of paper from soda bagasse pulp. Carbohydr Polym 194:1-8. https://doi. org/10.1016/j.carbpol.2018.04.026

Tanaka R, Saito T, Hondo H, Isogai A (2015) Influence of flexibility and dimensions of nanocelluloses on the flow properties of their aqueous dispersions. Biomacromolecules 16:2127-2131. https://doi.org/10.1021/acs. biomac.5b00539

Tu H, Yu Y, Chen J, Shi X, Zhou J, Deng H, Du Y (2017) Highly cost-effective and high-strength hydrogels as dye adsorbents from natural polymers: chitosan and cellulose. Polym Chem 8:2913-2921. https://doi.org/10.1039/c7py00223h

Velasquez-Cock J et al (2019) Influence of cellulose nanofibrils on the structural elements of ice cream. Food Hydrocolloid 87:204-213. https://doi.org/10.1016/j.foodhyd.2018.07. 035

Wu S, Tang Y, Xue G, Zhao Y (2010) Influence of CPAM/CMC layer-by-layer self-assembly on OCC fiber physical strength and surface properties. vol 3

Yang W, Bian H, Jiao L, Wu W, Deng Y, Dai H (2017) High wet-strength, thermally stable and transparent TEMPOoxidized cellulose nanofibril film via cross-linking with poly-amide epichlorohydrin resin. Rsc Adv 7:31567-31573. https://doi.org/10.1039/c7ra05009g

Yousefhashemi SM, Khosravani A, Yousefi H (2019) Isolation of lignocellulose nanofiber from recycled old corrugated container and its interaction with cationic starch-nanosilica combination to make paperboard. Cellulose 26:7207-7221. https://doi.org/10.1007/s10570-01902562-2

Zhang S-F, Zhao D-Y, Hou C (2018) Strengthening of polyacrylonitrile (PAN) fiber networks with polyamide epichlorohydrin (PAE) resin. Polym Bull 75:5373-5386. https://doi.org/10.1007/s00289-018-2334-x

Zhao Y, Li J, Rao QL, Cheng W (2014) Furnish pretreatment to improve paper strength aid performance in papermaking. Google Patents.

Publisher's Note Springer Nature remains neutral with regard to jurisdictional claims in published maps and institutional affiliations. 